\title{
Suicide Using an Air Blow Gun
}

DaeYoil Kim², JeongMok Kim², Solin Kim², YongHan Jung ${ }^{3}$, SangHan Lee ${ }^{4}$

${ }^{1}$ Scientific Investigation Department, Gyeongbuk Provincial Police Agency, Andong, Korea, ${ }^{2}$ Scientific Investigation Department, Gyeongnam Provincial Police Agency, Changwon, Korea, ${ }^{3}$ Forensic Medicine Division, National Forensic Service Busan Institute, Yangsan, Korea, ${ }^{4}$ Department of Forensic Medicine, Defense Institute of Forensic Science, Criminal Investigation Command, Ministry of National Defense, Seoul, Korea

Received: October 21, 2020 Revised: November 8, 2020

Accepted: February 18, 2021

\section{Correspondence to}

SangHan Lee

Department of Forensic Medicine, Defense Institute of Forensic Science, Criminal Investigation Command, Ministry of National Defense, 22 Itaewon-ro, Yongsan-gu, Seoul 04383, Korea

Tel: +82-2-748-1960

Fax: +82-2-748-1888

E-mail:sanghan111@gmail.com
An air blow gun is one of the most common pneumatic tools found at industrial sites and entrances of mountain trails in South Korea. It is used for spraying high-pressure air to dust off surfaces and clothes, and to inject air into tubes. There have been many reported cases of injuries and deaths associated with air blow guns. The victim died by placing the nozzle of an air blow gun, installed on an outdoor sports field, into her nose, and pulling the trigger. An autopsy ascribed her death to pneumothorax. Numerous accidents associated with air blow guns have been reported in the media. However, the use of an air blow gun has not been the subject of a suicide case study in forensic literature. To our knowledge, this is the first case report on suicide using an air blow gun. Stronger public safety warnings stressing the potentially fatal outcomes from careless usage of air blow guns are required.

Key Words: Air blow gun; Pneumothorax; Safety; Suicide

\section{Introduction}

Kancho, a Japanese word for enema, is a common prank among East Asian children. It is performed by clasping the hands together in the shape of a "gun" and poking at the unsuspecting victim's anus, while shouting "kan-CHO" [1]. There are records of the prank being practiced across Asia, and it is known by different names in different countries. In Korea, it is called Ttongchim. As children get used to the prank during 
childhood, they sometimes continue to practice it into adulthood. Without being fully aware of the risks of an air blow gun, perpetrators have been known to apply a compressed air gun to the anus of victims, either as a simple prank or with violent intent. Injecting air into the body by this method can lead to severe internal damage and death [1-7]. In addition to a literature review, we report a case in which a compressed air gun was used as a suicidal tool to cause an intentional pneumothorax.

\section{Case Report}

The victim was a 25-year-old single woman who worked as a physiotherapist. Recent disputes between the victim and her lover had resulted in significant emotional distress for her. The victim's body was found

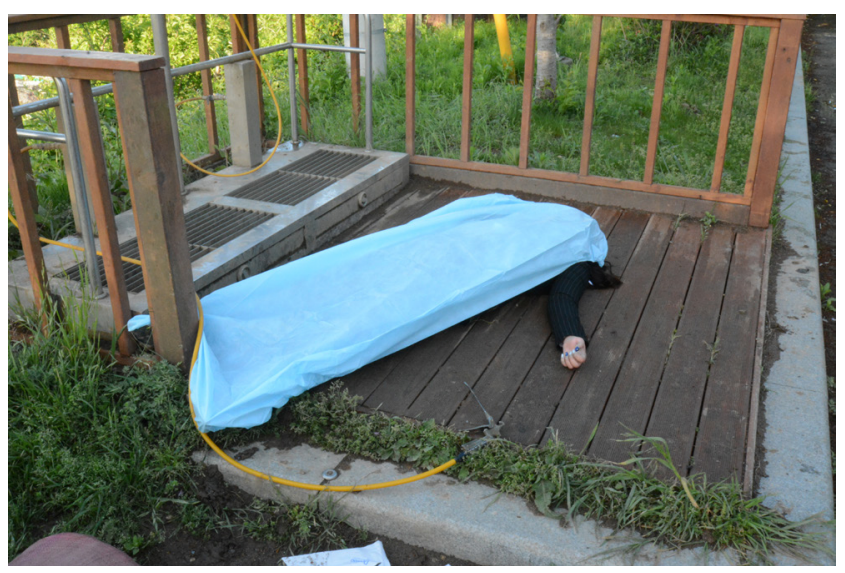

Fig. 1. The deceased lying supine with blood coming out from the nose and the air blow gun located near her left hand. A police officer has covered her body with a blue sheet.

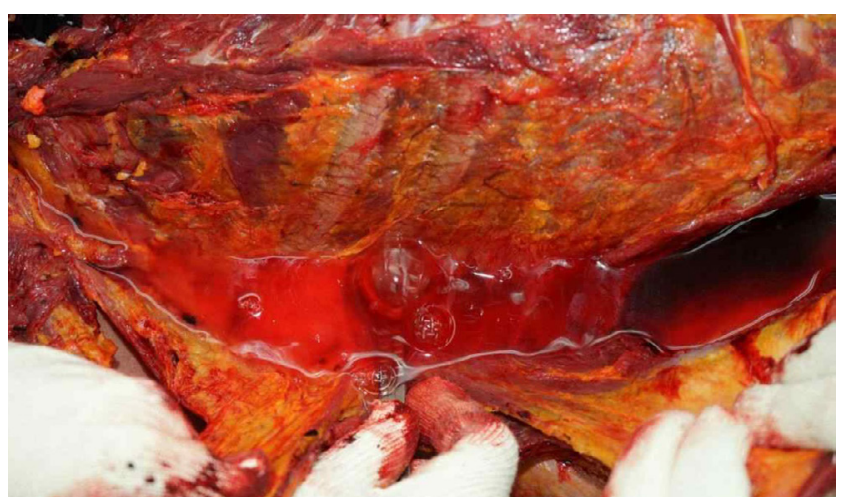

Fig. 2. Air bubbles are leaking through the chest wall from the right chest cavity after it was filled with water and a surgical scalpel was inserted and twisted.

on the wooden deck of a public air duster installed at the entrance of an outdoor sports field. The witness, who had been out for early morning exercise, called the police upon discovering the body. The deceased was lying supine and had blood on her face that had run down from the nose. There was a hose connected to an air compressor and a compressed air blow gun below her hand, beside her left leg (Fig. 1). Bloodstains were found on the air hose, on the bottom of the blow gun hanger, and on the bottom of the deck of the compressed air gun. No cardiopulmonary resuscitation was performed at the scene.

According to the autopsy report, the victim had a swollen face and subcutaneous emphysema in the whole body, including the chest, shoulders, and abdominal region. There were no hesitation marks on the wrists to indicate previous attempts of suicide. A pneumothorax test, performed by filling up the side of the chest with water and opening the thoracic cavity with an anatomical knife, revealed a positive result (Fig. 2). Both sides of the lungs were collapsed; $278 \mathrm{~g}$ on the left and $288 \mathrm{~g}$ on the right. There was blood foam within both sides of the major bronchial trees, and a 1 $\mathrm{cm}$ mucosal laceration on the left nasal turbinate (Fig. 3). The stomach contained small earring parts. Otherwise, there was no notable damage or pathological

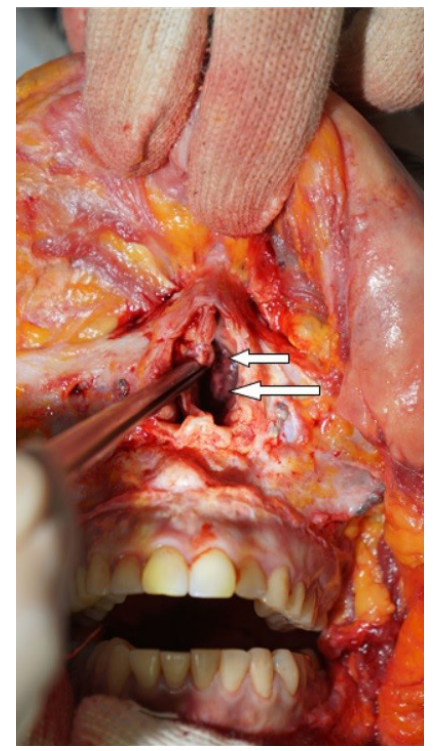

A

Fig. 3. (A, B) A linear mucosal laceration (arrows) is seen in the middle turbinate of the left nasal cavity. 


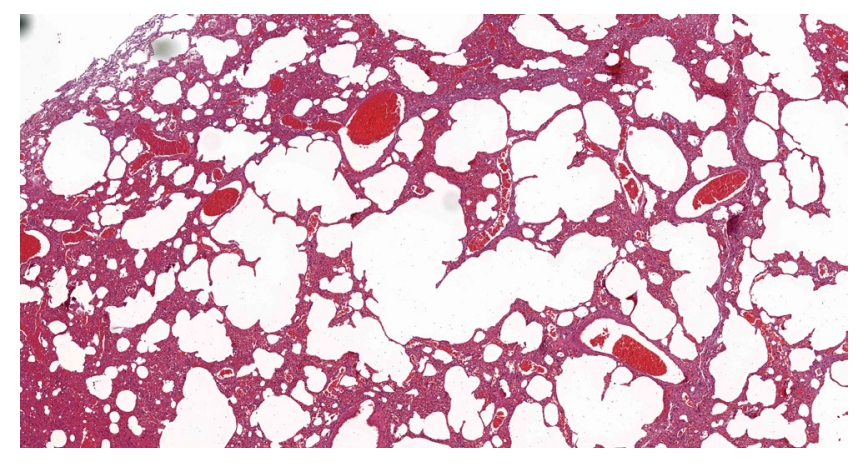

Fig. 4. Histologic $(\times 40)$ examination shows the irregularly dilated alveolar space with ruptured alveolar structures in all lobes of both lungs.

abnormality in the internal organs. Toxicology testing confirmed the presence of therapeutic concentrations of drugs such as antihistamines and expectorants. A blood ethyl alcohol test showed a value of less than $0.010 \%$. A histologic examination revealed a rupture of the irregularly expanded alveoli, and their walls in both lungs (Fig. 4).

No last will or suicide note was found among the victim's belongings at the scene of the incident, or at her residence. The victim's actions prior to the incident were determined using CCTV footage, credit card transaction history, and telecommunication investigation. A few hours prior to the incident, the victim had demonstrated odd behavior, such as spraying a fire extinguisher while being naked, purchasing an unusually large quantity of items from a convenience store, saying strange things that were out of context, throwing her belongings and the purchased products around, and running around an underground shopping complex barefoot. According to the psychiatric records of the victim, she had been diagnosed with bipolar disorder 2 years ago and had received treatment as an inpatient. Genetic testing of the bloodstains on the ground at the scene, and on the nozzle of the compressed air gun confirmed that the blood in both places was that of the victim. The integration of information about the circumstances of death, the scene of the incident, and the results of the autopsy and toxicology testing led to the conclusion of pneumothorax as the most important cause of death, and suicide as the manner of death.

\section{Discussion}

An air compressor pressurizes air to a level higher than the atmospheric pressure and stores it in a pneumatic system before it is used to supply power to a pneumatic tool. The air compressor is composed of a compressor body and a tank that stores the air. Depending on the application, the stored compressed air can be connected to various forms of pneumatic tools, such as nail guns, grinders, drivers, spray guns, and air blow guns. Although performance varies among different products, the normal injection pressure of an air compressor is 50 175 psi $\left(3.51-12.30 \mathrm{~kg} / \mathrm{cm}^{2}\right)[4,8]$. The air compressor installed at the scene of the incident had an injection pressure of $120 \mathrm{psi}\left(8.43 \mathrm{~kg} / \mathrm{cm}^{2}\right)$.

The deceased was assumed to have placed the nozzle of the compressed air gun inside her nose and subsequently used it to inject strongly compressed air through the nasal cavity. This ruptured the alveoli and caused an artificial pneumothorax, leading to death. Although an air embolism could also have occurred, it was not considered to have contributed to her death. The two main factors that determine the occurrence of an air embolism are the volume and accumulation rate of air that enters the blood circulation. The lethal volume of air for humans is $200-300 \mathrm{~mL}$ or $3-5 \mathrm{~mL} / \mathrm{kg}$ [9]. The autopsy confirmed a pneumothorax. Venous air embolism occurred as the air entered the venous system. This commonly occurs in medical procedures, especially during the insertion or removal of a venous catheter. It can also occur during neurosurgery, cesarean delivery, and abortion. Other causes of venous air embolism include injuries to the neck, head, and external genitalia [9], and damage to the endometrium and umbilical vein caused by sexual intercourse during pregnancy and autoerotic practices [10]. Usually, it resolves on its own, as only a small volume of air passes through the vein to reach the lungs, where gas bubbles are filtered in the alveoli and excreted. However, when a large gas bubble forms or when the gas bubble enters the heart or the brain through the vein, it can cause serious issues such as myocardial infarction, cardiac arrest, and cerebral air embolism.

Even without medical training, a person with minimal medical knowledge can intentionally or artificially 
cause pneumothorax and air embolism with suicidal intent. All intentional air embolism cases involve invasive methods, such as injection of a needle into the blood vessels or organs. Two methods are commonly used by patients or medical professionals. One, in which a nasal cannula is connected either to an oxygen supply device on the wall, or the nose to a venous catheter [11,12], and another, in which air is blown into a heparin lock [13]. In addition, there have been cases where a venous catheter in the arm was incorrectly connected to an oxygenator [14], and cases where the type of death is unclear [15]. There have also been exceptional cases of air embolism. A victim with a history of suicide attempts and megalomania built an air injection tool using a plastic bottle, an infusion set, and a dumbbell. He then used it to inject $2,000 \mathrm{~mL}$ of air into a vein in his arm [9]. Another victim died of autoerotism by injecting air into the glans using a refrigerator compressor, a rubber tube, and an injection needle [16]. An intentional pneumothorax can be observed in people with self-harm behaviors. Generally, these include patients with mental disorders who attempt suicide while in the hospital [17]. In the present case, the victim was a physiotherapist who had easy access to medical supplies and hospital facilities. Therefore, it could be considered quite unusual that she decided to use a public compressed air gun installed in an outdoor sports field. Before her death, the victim had been diagnosed with bipolar disorder and received treatment as an inpatient. The odd behaviors displayed by the victim before her death include saying unusual and strange things and running away after spraying a fire extinguisher while being naked at a residential shopping complex. An autopsy found two earring parts in the stomach contents. Spraying strongly compressed air into the nose causes unbearable pain. The fact that the victim nevertheless decided to do so to commit suicide can be considered a type of self-harm behavior. In most patients with bipolar disorder, the depressive phase is about three times longer than the manic phase. Moreover, female patients experience more depressive phases than male patients $[18,19]$.

Cases in which a compressed air blow gun was used in pranks or violence have sometimes been reported in the media $[1,2]$. However, it should be noted that such pranks can cause serious damage or death. Damage can occur even when the nozzle has not penetrated the anus, or when a victim has clothes on and maintains some distance [3]. The average pressure required to penetrate and rupture all the layers of human intestinal tissues is $4.07-5.9$ psi $\left(0.29-0.415 \mathrm{~kg} / \mathrm{cm}^{2}\right)$ [3-7]. A compressed air blow gun generates a powerful force that exceeds the average pressure of the anus of normal adults $\left(0.109 \mathrm{~kg} / \mathrm{cm}^{2}\right)$. It injects a large amount of air into the large intestine in a short time, and causes rapid expansion [6]. The strong air pressure causes damage and perforations in the large intestine [7]. Most injuries occur in the adjoining areas between the rectum and the S-shaped colon, and the small intestine [5]. In severe cases, acute respiratory failure and circulatory shock can lead to a fatal outcome [4]. If an air blow gun is directed towards the face, it can cause injuries around the eyes [8]. Moreover, the possibility that an air blow gun can be used for suicide as well as murder cannot be ruled out. McCorkell et al. [20] pointed out that it might be difficult to distinguish an industrial accident from a suicide attempt and even an attempted homicide in the case of nail gun injuries.

Numerous types of tools, products, and devices that offer convenience in everyday life and work can cause the same results. It should always be noted that accidents can happen at any time due to the mishandling of these tools and devices. It is important to keep reminding people of the dangers and risks of lethal injuries and death due to mishandling of equipment. It is difficult to prevent people from the malicious usage of these products on themselves or others. However, providing sufficient warnings and precautions for safety can prevent accidents. Compressed air blow guns are mostly installed near industrial facilities, workshops, mountain trail entrances and exits, and outdoor sports facilities. An air blow gun should never be pointed toward the face and certainly not used directly on the eyes, ears, nose, and mouth. Strong warnings must be issued against the use of air guns in pranks. In forensic practice and investigation processes, we must not neglect to examine how the tools and devices installed at the scene of the incident are operated, or to investigate a patient's medical records for a history of mental disorders. 
ORCID: DaeYoil Kim: https://orcid.org/0000-0002-92643307; JeongMok Kim: https://orcid.org/0000-00026765-2324; SoJin Kim: https://orcid.org/0000-00029903-7887; YongHan Jung: https://orcid.org/00000001-8547-0295; SangHan Lee: https://orcid.org/00000003-0390-3494

\section{Conflicts of Interest}

1. No potential conflict of interest relevant to this article was reported.

2. YongHan Jung, a contributing editor of the Korean Journal of Legal Medicine, was not involved in the editorial evaluation or decision to publish this article.

\section{References}

1. Mckay J. Man dies after friend blows air up his rectum in 'prank' gone wrong [Internet]. London: Metro; 2018 [cited 2020 Jun 16]. Available from: https://metro.co.uk/2018/07/15/man-dies-afterfriend-blows-air-up-his-rectum-in-prank-gone-wrong-7718081/.

2. Webb S. Child labourer, 10, dies after adult workers push air compressor line into his anus [Internet]. London: Daily Mirror; 2016 [cited 2020 Jun 16]. Available from: https://www.mirror. co.uk/news/world-news/child-labourer-10-dies-after-8487058.

3. Suh HH, Kim YJ, Kim SK. Colorectal injury by compressed air: a report of 2 cases.J Korean Med Sci 1996;11:179-82.

4. Kim SJ, Ahn SI, Hong KC, et al. Pneumatic colonic rupture accompanied by tension pneumoperitoneum. Yonsei Med J 2000;41:533-5.

5. Pahwa HS, Kumar A, Srivastava R, et al. Trans-anal barotrauma by compressed air leading to sigmoid perforation due to a dangerous practical joke. BMJ Case Rep 2012;2012:bcr2012006548.

6. Sy ED, Chiu YI, Shan YS, et al. Pneumatic colon injury following high pressure blow gun dust cleaner spray to the perineum. Int J Surg Case Rep 2015;6C:218-21.
7. Yin WB, Hu JL, Gao Y, et al. Rupture of sigmoid colon caused by compressed air. World J Gastroenterol 2016;22:3062-5.

8. Hiraoka T, Ogami T, Okamoto F, et al. Compressed air blast injury with palpebral, orbital, facial, cervical, and mediastinal emphysema through an eyelid laceration: a case report and review of literature. BMC Ophthalmol 2013;13:68.

9. Simon G, Racz E, Mayer M, et al. Suicide by intentional air embolism.J Forensic Sci 2017;62:800-3.

10. Pierucci G. Fatal air embolism during female autoerotic practice. Int J Legal Med 1991;104:241.

11. Laurent PE, Coulange M, Desfeux J, et al. Post-mortem computed tomography in a case of suicide by air embolism. Diagn Interv Imaging 2013;94:460-2.

12. Comment L, Varlet V, Ducrot K, et al. A fatal case of oxygen embolism in a hospital. Forensic Sci Res 2017;2:100-6.

13. Yanowitch P, Rosenthal R.A suicide attempt by blowing air into a heparin lock. Hosp Community Psychiatry 1994;45:382-3.

14. Takahashi Y, Sano R, Yasuda A, et al. Postmortem computed tomography evaluation of fatal gas embolism due to connection of an intravenous cannula to an oxygen supply. Leg Med (Tokyo) 2017;27:1-4

15. Tattoli L, Gauselmann H, Oesterhelweg L. Fatal gas embolism in hospital: accident or suicide? Forensic Sci Med Pathol 2020;16:528-30.

16. Modelli ME, Rodrigues MS, Castro BZ, et al. Self-induced fatal air embolism: accidental autoerotic death or suicide? J Forensic Sci 2013;58 Suppl 1:S261-3.

17. Gungor H, Duygu H, Yildiz BS, et al. A remnant sewing needle in the right ventricle as a cause of chest pain. Clin Cardiol 2010;33:E23-5.

18. Muller JK, Leweke FM. Bipolar disorder: clinical overview. Med Monatsschr Pharm 2016;39:363-9.

19. Karanti A, Kardell M, Joas E, et al. Characteristics of bipolar I and II disorder: a study of 8766 individuals. Bipolar Disord 2020;22:392-400.

20. McCorkell SJ, Harley JD, Cummings D. Nail-gun injuries: accident, homicide, or suicide? Am J Forensic Med Pathol 1986;7:192-5. 